\title{
Prevalence and Correlates of Hypertension Unawareness among Lebanese Adults: The Need to Target Those "Left Behind"
}

\author{
Fatima Ghaddar $\left(\mathbb{D},{ }^{1}\right.$ Lama Hammad ${ }^{D},{ }^{1}$ Rania A. Tohme $\mathbb{D}^{1,2}$ \\ Tamar Kabakian-Khasholian $\mathbb{D}^{1},{ }^{1}$ Nahla Hwalla $\mathbb{D}^{3},{ }^{3}$ and Abla M. Sibai $\mathbb{D D}^{1}$ \\ ${ }^{1}$ Faculty of Health Sciences, American University of Beirut, Beirut, Lebanon \\ ${ }^{2}$ Centers for Disease Control and Prevention, Atlanta, Georgia, USA \\ ${ }^{3}$ Faculty of Agriculture and Food Sciences, American University of Beirut, Beirut, Lebanon \\ Correspondence should be addressed to Abla M. Sibai; am00@aub.edu.lb
}

Received 19 August 2020; Accepted 3 February 2021; Published 25 February 2021

Academic Editor: Kai Hu

Copyright (c) 2021 Fatima Ghaddar et al. This is an open access article distributed under the Creative Commons Attribution License, which permits unrestricted use, distribution, and reproduction in any medium, provided the original work is properly cited.

\begin{abstract}
Introduction. Hypertension unawareness is context-specific, and our understanding of factors associated with it has implications on primary healthcare practices locally and contributes to achieving cardiovascular disease (CVD) targets, globally. In this study, we examine the prevalence and correlates of hypertension unawareness among adult Lebanese population. Methods. The study sample included a nationally representative sample of 2214 adults $\geq 25$ years of age from the Noncommunicable Disease (NCD) Risk Factor WHO-STEPS cross-sectional survey conducted in Lebanon. In the first step, hypertension was assessed based on reported morbidity using face-to-face interviews, and in the second step, based on blood pressure (BP) measurement. We defined hypertension prevalence as systolic/diastolic blood pressure $\geq 140 / 90 \mathrm{mmHg}$ and/or ongoing treatment for hypertension. Hypertension unawareness was described as lack of prior knowledge of hypertensive status. Those responding negatively to the faceto-face interview question "whether they had ever been told by a health worker that they have hypertension" were labelled as "apparently healthy." Results. Overall prevalence of hypertension was $30.7 \%$. A total of 369 subjects were unaware of their condition, representing $51.8 \%$ of all hypertensives and $15.9 \%$ of the apparently healthy. Multivariable analysis controlling for a number of confounders showed that, among apparently healthy participants, insurance coverage and contact with healthcare services were not associated with higher likelihood for hypertension awareness. Among all hypertensives, hypertension unawareness was significantly higher in the young, those with BMI $<25 \mathrm{~kg} / \mathrm{m}^{2}$ (adjusted OR (aOR): 2.52; 95\% CI: 1.35-4.69), no CVD (aOR: 3.30; 95\% CI: 1.74-6.29), and participants with no reported family history of hypertension (aOR: 4.87; 95\% CI: 2.89-8.22), compared to their counterparts. Conclusion. In Lebanon, unawareness of hypertension occurred in those clinically least perceived to be at risk. These findings are key for optimizing current screening practices and informing NCD prevention efforts in the country and contribute to achieving global targets of the SDGs of "leaving no one behind."
\end{abstract}

\section{Introduction}

Hypertension is a major public health problem and a leading cause for cardiovascular disease (CVD) morbidity and mortality globally [1]. In 2016 alone, high blood pressure constituted $8.9 \%$ of global disability-adjusted life years (DALYs) and accounted for around 10.5 million deaths [2]. Hypertension unawareness is an important determinant of associated morbidity, notably in economically developing countries and in settings with limited access to healthcare
$[3,4]$. A recent systematic analysis of population-based studies from 90 countries worldwide estimated that over half of adults with hypertension are unaware of their condition, with low- and middle-income countries having almost double the proportion of unawareness as compared to that in high-income countries (62.1\% versus 33\%) [5].

Despite ample evidence on prevalence rates of hypertension unawareness, studies examining differentials by covariates remain limited in the global literature and with varying results. For example, whilst a number of studies note 
that male gender and young age are associated with hypertension unawareness [6-9], others have shown that women [10] and older age groups had worse levels of awareness [11, 12]. Furthermore, only a few studies have examined and/or controlled for access to and use of health services, which are important determinants of hypertension identification $[13,14]$.

Lebanon is a small, highly urbanized, upper middleincome country in the Middle East (with a population of 4.5 million and over $85 \%$ urbanization rate). As elsewhere in the region, CVDs are the most prevalent health conditions in Lebanon and the leading cause of death $[15,16]$, Recent initiatives to address this problem by the Ministry of Public Health included the integration of a noncommunicable disease (NCD) program in 2012, which covers screening for hypertension within its primary healthcare network, and the launching of a nation-wide awareness campaign for hypertension screening in 2019 [17, 18]. However, such initiatives remain uninformed by baseline data, and data on hypertension prevalence and unawareness are, in fact, scarce. Previous research on hypertension in Lebanon was either based on reported morbidity [19] or focused on the clinical manifestation and control of hypertension [20, 21]. Only one study considered hypertension unawareness as part of a much wider research question on hypertension prevalence, treatment, and control; still, the study did not include detailed assessment of correlates of hypertension unawareness [22].

In this paper, we take a closer look on the magnitude of hypertension unawareness in Lebanon, making use of a nation-wide representative data that were collected as part of the WHO-STEPS standardized global surveys, and examine its association with sociodemographic and health-related characteristics. More specifically, this study aims at investigating two research questions, the first examines whether lack of access to and infrequent use of healthcare are potential factors that deter detection of hypertension, and the second examines whether sociodemographic and clinical characteristics and other health-related factors are potentially associated with hypertension unawareness. Hypertension is amenable to intervention, and the extent of our understanding of disparities in awareness rates across various sociodemographic subpopulations and health characteristics is key to informing national efforts in planning appropriate and relevant screening programs and has implications for early diagnosis and treatment.

\section{Materials and Methods}

2.1. Study Design and Fieldwork. Data for this study are drawn from the nation-wide Nutrition and Noncommunicable Disease Risk Factor (NNCD-RF) survey wave of 2009, which was conducted in Lebanon on a nationally representative sample of 2276 individuals, aged 25 years and above. Using multistage cluster survey design, with households representing the primary sampling units, one adult was randomly selected from each household roster. Pregnant and/or lactating women and individuals with mental disabilities or learning difficulties were excluded.
Care was taken such that the sample was proportional to the age, sex, and district distribution of the baseline population in Lebanon, as per the data provided by the Central Administration of Statistics.

Data collection followed the WHO-STEPS crosssectional survey methodology and instruments [23]. In the first step, face-to-face interviews were conducted eliciting information on socioeconomic characteristics, risk behaviors, reported comorbidities (including hypertension), healthcare use, and insurance coverage. In the second step, blood pressure (BP) and anthropometric measurements (height and weight) were taken using standardized techniques and calibrated equipment. Measurement of BP was done using a mercury sphygmomanometer after subjects were seated and rested for at least 10 minutes. In accordance with the WHO-STEPS guidelines and international literature [24], two consecutive measures were taken 5 minutes apart and the average of the two was considered the final BP measure. Fieldwork was carried out mostly by nutrition graduates who attended a three-day training workshop covering interviewing skills, and anthropometric and BP measurement techniques. Informed consent was obtained from all participants. Further details on the NNCD-RF surveillance study methods are presented elsewhere [25]. The study was approved by the Institutional Review Board (IRB) of the American University of Beirut, and data collected were deidentified to allow for subsequent research that would be exempted from further IRB approval. A total of 62 study participants did not have a BP measurement in the survey data, yielding a sample of 2214 subjects available for analysis in the present study.

2.2. Measures. Data from reported hypertension in the first step and from measured blood pressure in the second step yielded four mutually exclusive groups (Table 1). In our study, we defined hypertension prevalence, according to the World Hypertension League [26], as systolic BP (SBP) $\geq 140 \mathrm{mmHg}$, and/or diastolic BP (DBP) $\geq 90 \mathrm{mmHg}$, and/or the presence of an ongoing treatment for hypertension (this corresponds to Groups A, B, and C in Table 1). Hypertension unawareness (which will be used interchangeably with "newly diagnosed hypertension" in this manuscript) was defined as unknown prior knowledge of being hypertensive (Group C). Also, we describe participants responding positively to the face-to-face interview question "whether they had ever been told by a health worker that they have hypertension" as "aware" (Groups A and B) and those responding negatively as "apparently healthy" (Group C and D) individuals.

Covariates associated with hypertension unawareness were examined in three broad clusters: socioeconomic characteristics, access and use of healthcare, and clinical profile and risk behavior. Socioeconomic characteristics included age (25-44 years, 45-64 years, and $\geq 65$ years), gender, marital status (ever and never married), educational level (illiterate/reads and writes, primary/complementary education, secondary/technical education, and university/ higher education), and work status (not working, working, 
TABLE 1: Mapping self-reported hypertension based on face-to-face interviews against hypertension based on blood pressure measurements.

\begin{tabular}{|c|c|c|c|}
\hline \multirow{2}{*}{ Self-reported hypertension } & \multicolumn{2}{|c|}{$\begin{array}{c}\text { Hypertension status based on } \mathrm{BP}^{*} \\
\text { measurement }\end{array}$} & \multirow{2}{*}{ Total } \\
\hline & High BP & Normal BP & \\
\hline Positive & $\begin{array}{l}226 \\
(\mathrm{~A})\end{array}$ & $\begin{array}{l}162 \\
\text { (B) }\end{array}$ & $\begin{array}{c}388 \\
(\mathrm{~A}+\mathrm{B}) \\
(\text { aware })\end{array}$ \\
\hline Negative & $\begin{array}{c}369 \\
(\mathrm{C}) \\
\text { (unaware) }\end{array}$ & $\begin{array}{c}1457 \\
\text { (D) } \\
\text { (normotensive) }\end{array}$ & $\begin{array}{c}1826 \\
(\mathrm{C}+\mathrm{D}) \\
\text { (apparently healthy) }\end{array}$ \\
\hline Total & 595 & 1619 & 2214 \\
\hline
\end{tabular}

${ }^{*} \mathrm{BP}=$ blood pressure.

and retired). Health insurance coverage was analyzed as dichotomous variable (yes/no), and use of care was measured as contact with a health professional in the six months prior to the survey (yes/no), the last time participants had their BP measured, and the last time they had their blood being tested for sugar or lipid levels (past year, 1-2 years, $\geq 3$ years, and never). For the clinical characteristics, we examined the body mass index (BMI) (calculated as weight in kilograms divided by the square of height in meters $\left(\mathrm{kg} / \mathrm{m}^{2}\right)$, self-reported diabetes mellitus, high lipids, cardiovascular or cerebrovascular disease (which includes heart disease, myocardial infarction, stroke, and/or peripheral vascular disease), and family history of hypertension. BMI was categorized as normal weight $(\mathrm{BMI}<25)$, overweight $(25 \leq \mathrm{BMI} \leq 29)$, and obese $(\mathrm{BMI} \geq 30)$. Risk behaviors included smoking cigarettes and/or waterpipe (yes/no), alcohol consumption categorized as none, moderate $(\leq$ twice per week), and heavy (three times per week), physical activity (low, moderate, and high intensity), and salt intake ( $\leq 2300 \mathrm{mg} /$ day, $>2300 \mathrm{mg} /$ day) [27]. Physical activity was assessed using the short version of the International Physical Activity Questionnaire (IPAQ). The classification of physical activity is based on duration (minutes per day) and frequency (days per week) of engagement in various levels of physical activity (walking, moderate, and vigorous-intensity activities) [28].

2.3. Analyses. Data were weighted to account for selection probability of households within each administrative district in Lebanon and for individuals within each household, and descriptive statistics expressed as frequencies and percentages were generated to describe the study sample. The prevalence of hypertension and hypertension unawareness were estimated in the total sample and stratified by age and gender. Multivariable regression analyses were then conducted within an analytical framework addressing our two research questions. In the first one, we examined whether lack of access to and infrequent use of healthcare were factors that impede detection of hypertension and hence increase unawareness rate (refer to Section 2.2 for details on healthcare access and use factors). To answer this, we focused on the apparently healthy participants ( $C$ and $D$, Table 1), studying the association of insurance coverage and frequency of contact with health services, examined individually, with unaware hypertensives (C) compared to those who are normotensive (D). The reason we exclude individuals already aware of their condition in this step is to evade the potential bias of "reverse causality," in which diagnosis of hypertension would act as the cause for a person's more frequent pattern of healthcare use rather than a consequence of contact with healthcare services [29]. In this step, logistic regression analyses were conducted, while adjusting for age and gender, education, and insurance (except for the model studying "insurance coverage," which adjusted for age, gender, and education only). For the second research question, we examined whether sociodemographic characteristics and health-related factors were potentially associated with hypertension unawareness (refer to Section 2.2 for details on sociodemographic, clinical, and healthrelated factors). For this question, we included all individuals with hypertension (A, B, and $\mathrm{C}$, Table 1) and compared characteristics between the unaware (C) and the aware groups (A and $\mathrm{B})$. In this stage, the multivariable logistic regression analysis was conducted, while adjusting for health insurance coverage, last time BP was measured, and contact with a health professional within six months prior to the survey.

Odds ratios (ORs) and 95\% confidence intervals (95\% CIs) were calculated, with reference categories of the covariates conceptually chosen to represent those anticipated to have lower odds of being unaware, relying on the literature and on our theoretical understanding of the associations. Analyses were conducted using the Statistical Package for Social Sciences (SPSS, version 21.0), and a $p$ value less than 0.05 was considered statistically significant.

\section{Results}

3.1. Description of Study Population. Characteristics of the study population are summarized in Table 2 . The median age of the participants was 40 years (interquartile range: 32 to 50 years), with the majority being in the 25-44-year age group $(61.5 \%)$. Close to $44 \%$ were men, $79.4 \%$ were ever married, $22.8 \%$ had a university/higher education degree, and $50.2 \%$ were working at the time of the survey. Most of the participants reported access to insurance coverage (57.8\%), and $45 \%$ reported having visited a health professional at least 
TABle 2: Descriptive characteristics of study participants.

\begin{tabular}{|c|c|c|}
\hline \multirow{3}{*}{ Variables } & \multicolumn{2}{|c|}{ Total } \\
\hline & \multicolumn{2}{|c|}{$N=2214$} \\
\hline & $n$ & $\%$ \\
\hline \multicolumn{3}{|l|}{ Socioeconomic characteristics } \\
\hline \multicolumn{3}{|l|}{ Age (years) } \\
\hline $25-44$ & 1254 & 61.5 \\
\hline $45-64$ & 676 & 29.6 \\
\hline 65 and above & 284 & 8.9 \\
\hline Median (interquartile range) & \multicolumn{2}{|c|}{$(32-50)$} \\
\hline Gender (\% male) & 1017 & 44.2 \\
\hline Marital status (\% ever married) & 1733 & 79.4 \\
\hline \multicolumn{3}{|l|}{ Educational level } \\
\hline Illiterate/reads and writes & 196 & 8.1 \\
\hline Primary/complementary education & 928 & 44.2 \\
\hline Secondary/technical education & 565 & 24.9 \\
\hline University or higher education & 525 & 22.8 \\
\hline \multicolumn{3}{|l|}{ Work status } \\
\hline Not working (includes housewives) & 933 & 44.7 \\
\hline Working & 1148 & 50.2 \\
\hline Retired & 132 & 5.0 \\
\hline \multicolumn{3}{|l|}{ Access and use of healthcare } \\
\hline Insurance coverage ( $\%$ yes) & 1321 & 57.8 \\
\hline Visited health professional in last 6 months (\% yes) & 1009 & 45.0 \\
\hline \multicolumn{3}{|c|}{ Last time measured blood pressure (BP) } \\
\hline Past year & 1349 & 58.6 \\
\hline $1-2$ years & 342 & 16.4 \\
\hline$\geq 3$ years & 200 & 9.8 \\
\hline Never & 323 & 15.2 \\
\hline \multicolumn{3}{|c|}{ Last time measured either blood sugar or blood lipids } \\
\hline Past year & 1153 & 49.3 \\
\hline $1-2$ years & 360 & 16.0 \\
\hline$\geq 3$ years & 200 & 9.8 \\
\hline Never & 501 & 24.9 \\
\hline \multicolumn{3}{|l|}{ Clinical profile and risk behavior } \\
\hline Smoking (cigarette and/or waterpipe) (\% yes) & 1309 & 58.7 \\
\hline \multicolumn{3}{|l|}{ Physical activity } \\
\hline Low-intensity activity & 1017 & 45.1 \\
\hline Moderate-intensity activity & 707 & 32.0 \\
\hline High-intensity activity & 476 & 22.9 \\
\hline \multicolumn{3}{|l|}{ Salt intake } \\
\hline$\leq 2300 \mathrm{mg} /$ day & 990 & 44.8 \\
\hline$>2300 \mathrm{mg} /$ day & 1125 & 55.2 \\
\hline \multicolumn{3}{|l|}{ Alcohol } \\
\hline None & 1303 & 63.8 \\
\hline Moderate drinking & 789 & 31.6 \\
\hline Heavy drinking & 122 & 4.6 \\
\hline \multicolumn{3}{|l|}{ BMI } \\
\hline Normal weight $(<25)$ & 709 & 33.7 \\
\hline Overweight (25-29) & 813 & 37.3 \\
\hline Obese $(\geq 30)$ & 621 & 29.0 \\
\hline Self-reported high lipids (\% yes) & 411 & 16.7 \\
\hline Self-reported cardiovascular disease $(\mathrm{CVD})^{*}$ (\% yes) & 196 & 7.7 \\
\hline Self-reported diabetes mellitus (DM) (\% yes) & 181 & 7.4 \\
\hline Family history of hypertension (\% yes) & 1353 & 61.5 \\
\hline
\end{tabular}

${ }^{*}$ CVD included heart disease, myocardial infarction, stroke, and/or peripheral vascular disease.

once in the six months prior to the survey. Also, 58.6\% had their BP measured, and $49.3 \%$ had their blood tested for either sugar or lipids in the year prior to the survey. Close to
$59 \%$ were current smokers, $45.1 \%$ were involved in lowintensity physical activity, $55.2 \%$ consumed $>2300 \mathrm{mg}$ of salt per day, $4.6 \%$ were heavy drinkers, and $29 \%$ were obese. Hyperlipidemia topped the list of reported comorbid conditions (16.7\%), followed by heart disease (7.7\%) and diabetes $(7.4 \%)$, and close to $62 \%$ reported a family history of hypertension.

Of the 2214 study participants, 757 (30.7\%) were classified as individuals with hypertension (Figure 1). Of these, $369(51.8 \%)$ were unaware of having hypertension. Men were significantly more likely than women to be hypertensive $(42.0 \%$ vs. $21.8 \%)$ and to be unaware of their condition $(61.1 \%$ vs. $37.5 \%)$. Whilst hypertension prevalence increased significantly with increasing age reaching $73.2 \%$ among those aged $\geq 65$ years, the percentage of those unaware decreased with increasing age reaching $25.2 \%$ in the higher age groups.

3.2. Correlates of Hypertension Unawareness among Apparently Healthy Participants. Among apparently healthy participants, $15.9 \%$ were unaware of having elevated BP; that is, they were newly diagnosed upon measurement. Table 3 shows the results for the associations between access to and use of healthcare services with hypertension unawareness compared to normotensive participants. Lack of access to health insurance did not increase the odds of being unaware $(\mathrm{OR}=0.99 ; 95 \% \mathrm{CI}=0.76-1.29)$. Similarly, none of the healthcare use variables were significantly associated with hypertension unawareness.

3.3. Correlates of Hypertension Unawareness among All Hypertensive Participants. Table 4 shows the associations of sociodemographic and health-related factors with hypertension unawareness, for those who were unaware of their elevated BP as compared to those who were aware of their condition. Hypertension unawareness decreased significantly with increasing age (adjusted OR $(\mathrm{aOR})=0.44,95 \%$ $\mathrm{CI}=0.26-0.74$ for the $45-64$-year age group; $\mathrm{aOR}=0.12$, $95 \% \mathrm{CI}=0.05-0.26$ for the $\geq 65$-year age group). Participants with "healthier" clinical profile including those with a normal $\mathrm{BMI}<25(\mathrm{aOR}=2.52,95 \% \mathrm{CI}=1.35-4.69)$, no reported CVD $(\mathrm{aOR}=3.30,95 \% \mathrm{CI}=1.74-6.29)$, and those who did not report a family history of hypertension $(\mathrm{aOR}=4.87,95 \% \mathrm{CI}=2.89-8.22)$ were at higher odds of being unaware of their condition, even after controlling for potential covariates such as health insurance coverage, last time BP was measured, and contact with a health professional within six months prior to the survey.

\section{Discussion}

Findings from this study reveal a relatively high burden of hypertension among Lebanese adults aged 25 years and older $(30.7 \%)$. Notably, $52 \%$ of all hypertensive individuals were unaware of their condition. Hypertension unawareness was found to be greater in the younger age groups and was likely to be occurring under the "watchful eye," a term coined by Hyman and Pavlik [29], of the 


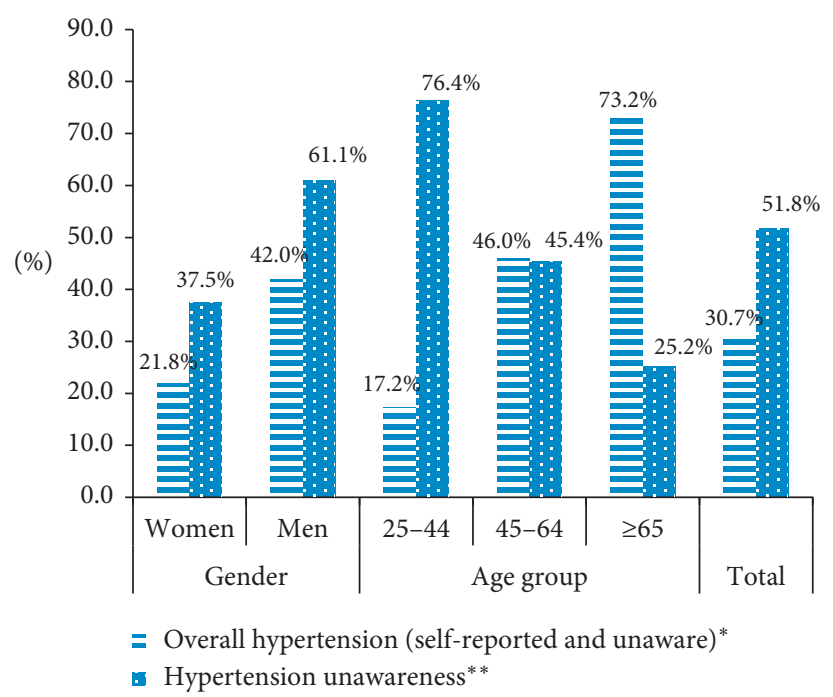

FIGURE 1: Prevalence of hypertension and hypertension unawareness in the total sample, and by age and gender, NNCD-RF WHO-STEPS survey, Lebanon; * weighted prevalence of hypertension, calculated with the denominator being the total sample; ** weighted prevalence of hypertension unawareness, calculated with the denominator being hypertensive individuals.

TABLE 3: Access and use of healthcare services among apparently healthy participants: comparison of hypertension unaware group with the normotensive.

\begin{tabular}{|c|c|c|c|c|c|}
\hline Variables & $\begin{array}{c}\text { Normotensive (Group D) } \\
n(\%)^{* *}\end{array}$ & $\begin{array}{l}\text { Hypertension unaware (Group C) } \\
n(\%)^{* *}\end{array}$ & $\mathrm{aOR}^{*}$ & $95 \% \mathrm{CI}$ & $p$ value \\
\hline Total & $1457(84.1)$ & $369(15.9)$ & & & \\
\hline \multicolumn{6}{|c|}{ Insurance coverage } \\
\hline Yes & $877(81.6)$ & $217(18.4)$ & 1.00 & & \\
\hline No & $577(81.0)$ & $151(19.0)$ & 0.99 & $0.76-1.29$ & 0.95 \\
\hline \multicolumn{6}{|c|}{ Visited health professional in last 6 months } \\
\hline Yes & $628(83.9)$ & $133(16.1)$ & 1.00 & & \\
\hline No & $829(79.6)$ & $235(20.4)$ & 1.12 & $0.86-1.45$ & 0.41 \\
\hline \multicolumn{6}{|c|}{ Last time measured blood pressure (BP) } \\
\hline Past year & $788(80.3)$ & $214(19.7)$ & 1.00 & & \\
\hline $1-2$ years & $245(80.6)$ & $64(19.4)$ & 1.16 & $0.82-1.63$ & 0.41 \\
\hline$\geq 3$ years & $159(82.3)$ & $34(17.7)$ & 0.84 & $0.55-1.29$ & 0.43 \\
\hline Never & $265(84.5)$ & $57(15.5)$ & 0.75 & $0.52-1.08$ & 0.12 \\
\hline \multicolumn{6}{|c|}{ Last time had their blood tested for sugar or blood lipids levels } \\
\hline Past year & $647(78.9)$ & $187(21.1)$ & 1.00 & & \\
\hline 1-2 years & $253(81.3)$ & $64(18.7)$ & 0.99 & $0.70-1.42$ & 0.97 \\
\hline$\geq 3$ years & $158(84.3)$ & $31(15.7)$ & 0.79 & $0.51-1.24$ & 0.31 \\
\hline Never & $399(84.0)$ & $87(16.0)$ & 0.73 & $0.53-1.01$ & 0.06 \\
\hline
\end{tabular}

*aOR: each of these variables was entered separately in four logistic models, with odds ratio being adjusted for age, gender, education, and insurance (except in the first one which adjusted for age, gender, and education only). ${ }^{* *} \%$ is estimated based on weighted data.

Lebanese healthcare system. Hypertension unawareness was not associated with the frequency of contact with physicians nor with the use of healthcare services. Also, participants with low clinical risk profiles were at higher odds of being unaware of their condition. These results challenge potential presumptions that a patient unaware of his/her hypertension condition is an older adult with limited access to the healthcare system. Our study findings have implications for screening practices within primary healthcare and for health promotion efforts targeting hypertension unawareness in the Lebanese population at large.
In our study, close to one-third of the adult population were hypertensives, and this appears to be broadly lower than previously published estimates from the country and fall in the midrange of data reported from the region. Matar et al. [22], for example, using the same definition of hypertension as ours, reported a slightly higher rate of $36.9 \%$ in a national sample of adults 21 years of age and older. A systematic review of several studies from the region estimated a mean hypertension prevalence rate of $29.5 \%$, with figures ranging between $25.2 \%$ in Oman and $39.6 \%$ in Morocco [30]. More recent studies have shown comparable figures from Saudi Arabia (27.2\% among those aged 30 years 
TABLE 4: Socioeconomic and health characteristics among hypertensives: comparison of hypertension unaware group with hypertension aware.

\begin{tabular}{|c|c|c|c|c|c|}
\hline & $\begin{array}{l}\text { Hypertension aware (Groups A and B) } \\
n(\%)^{*}\end{array}$ & $\begin{array}{l}\text { Hypertension unaware (Group C) } \\
n(\%)^{*}\end{array}$ & $\mathrm{aOR}^{* *}$ & $95 \% \mathrm{CI}$ & $\begin{array}{c}p \\
\text { value }\end{array}$ \\
\hline Total & $388(48.2)$ & $369(51.8)$ & & & \\
\hline \multicolumn{6}{|l|}{ Age (years) } \\
\hline $25-44$ & $49(23.6)$ & $176(76.4)$ & & & \\
\hline $45-64$ & $182(54.6)$ & $140(45.4)$ & 0.44 & $0.26-0.75$ & $<0.01$ \\
\hline 65 and above & $157(74.8)$ & $53(25.2)$ & 0.12 & $0.05-0.28$ & $<0.01$ \\
\hline \multicolumn{6}{|l|}{ Gender } \\
\hline Female & $212(62.5)$ & $108(37.5)$ & 1.00 & & \\
\hline Male & $176(38.9)$ & $261(61.1)$ & 1.41 & $0.68-2.92$ & 0.36 \\
\hline \multicolumn{6}{|l|}{ Marital status } \\
\hline Ever married & $359(52.1)$ & $292(47.9)$ & 1.00 & & \\
\hline Never married & $29(21.4)$ & $77(78.6)$ & 1.53 & $0.70-3.33$ & 0.28 \\
\hline \multicolumn{6}{|l|}{ Educational level } \\
\hline $\begin{array}{l}\text { University or higher } \\
\text { education }\end{array}$ & $54(40.6)$ & $68(59.4)$ & 1.00 & & \\
\hline Secondary/technical school & $66(37.9)$ & $101(62.1)$ & 1.48 & $0.75-2.92$ & 0.26 \\
\hline Primary/complementary & $180(46.9)$ & $170(53.1)$ & 1.31 & $0.70-2.45$ & 0.41 \\
\hline Illiterate/reads and writes & $88(77.2)$ & $30(22.8)$ & 1.36 & $0.55-3.37$ & 0.51 \\
\hline \multicolumn{6}{|l|}{ Work status } \\
\hline $\begin{array}{l}\text { Not working (including } \\
\text { housewives) }\end{array}$ & $209(64.6)$ & $100(35.4)$ & 1.00 & & \\
\hline Working & $123(32.2)$ & $239(67.8)$ & 1.61 & $0.77-3.37$ & 0.21 \\
\hline Retired & $56(63.6)$ & $30(36.4)$ & 1.31 & $0.52-3.29$ & 0.56 \\
\hline \multicolumn{6}{|l|}{$\begin{array}{l}\text { Smoking (cigarette and/or } \\
\text { waterpipe) }\end{array}$} \\
\hline Yes & $236(47.3)$ & $244(52.7)$ & 1.00 & & \\
\hline No & $152(50.0)$ & $125(50.0)$ & 0.79 & $0.50-1.25$ & 0.32 \\
\hline \multicolumn{6}{|l|}{ Physical activity } \\
\hline Low-intensity activity & $177(47.5)$ & $178(52.5)$ & 1.00 & & \\
\hline Moderate-intensity activity & $132(49.5)$ & $114(50.5)$ & 1.25 & $0.77-2.03$ & 0.37 \\
\hline High-intensity activity & $76(47.4)$ & $75(52.6)$ & 1.02 & $0.56-1.85$ & 0.95 \\
\hline \multicolumn{6}{|l|}{ Salt intake } \\
\hline$>2300 \mathrm{mg} /$ day & $132(35.3)$ & $217(64.7)$ & 1.00 & & \\
\hline$\leq 2300 \mathrm{mg} /$ day & $232(61.2)$ & $133(38.8)$ & 0.78 & $0.50-1.23$ & 0.29 \\
\hline \multicolumn{6}{|l|}{ Alcohol } \\
\hline Heavy drinking & $24(37.8)$ & $33(62.2)$ & 1.00 & & \\
\hline Moderate drinking & $134(47.2)$ & $133(52.8)$ & 1.24 & $0.48-3.18$ & 0.66 \\
\hline None & $230(49.9)$ & $203(50.1)$ & 1.81 & $0.70-4.68$ & 0.22 \\
\hline \multicolumn{6}{|l|}{ BMI } \\
\hline Obese $(\geq 30)$ & $187(53.5)$ & $139(46.5)$ & 1.00 & & \\
\hline Overweight (25-29) & $130(47.6)$ & $136(52.4)$ & 1.14 & $0.71-1.83$ & 0.58 \\
\hline Normal weight $(<25)$ & $48(33.9)$ & $81(66.1)$ & 2.49 & $1.33-4.64$ & $<0.01$ \\
\hline \multicolumn{6}{|l|}{ Self-reported diabetes mellitus } \\
\hline Yes & $89(70.5)$ & $36(29.5)$ & 1.00 & & \\
\hline No & $299(43.8)$ & $333(56.2)$ & 1.12 & $0.62-2.05$ & 0.70 \\
\hline \multicolumn{6}{|l|}{ Self-reported high lipids } \\
\hline Yes 1 & $169(67.2)$ & $66(32.8)$ & 1.00 & & \\
\hline No & $219(39.9)$ & $303(60.1)$ & 1.43 & $0.90-2.27$ & 0.13 \\
\hline \multicolumn{6}{|l|}{$\begin{array}{l}\text { Self-reported cardiovascular } \\
\text { disease (CVD) }\end{array}$} \\
\hline Yes & $123(82.4)$ & $25(17.6)$ & 1.00 & & \\
\hline No & $265(40.8)$ & $344(59.2)$ & 3.26 & $1.72-6.19$ & $<0.01$ \\
\hline \multicolumn{6}{|l|}{ Family history of hypertension } \\
\hline Yes & $284(56.0)$ & $196(44.0)$ & 1.00 & & \\
\hline No & $104(33.8)$ & $173(66.2)$ & 4.76 & $2.82-8.03$ & $<0.01$ \\
\hline
\end{tabular}

${ }^{*} \%$ is estimated based on weighted data. ${ }^{* *}$ aOR: odds ratio adjusted for all variables in the table and additionally to health insurance coverage, last time measured BP, and visit of health professional in the six months prior to the survey.

or older) [31] and Palestine (27.6\% among those aged 25 years or older) [32] and from the Prospective Urban Rural Epidemiology (PURE) study enrolling participants from 87 urban and rural communities from four countries in the Middle East (33\%) [33]. Indeed, it is difficult to provide a valid comparison across studies owing to variations in the 
age of participants, gender mix, the setting of the study (national versus regional and rural versus urban), and operator-related bias in following standard blood pressure measurement techniques and guidelines. Ideally, collaborative efforts would be needed nationally and regionally to conduct multicountry comparisons, standardized in both hypertension measurements and definitions.

Hypertension unawareness is context-specific and has been shown to vary widely across countries and regions. In our study, $15.9 \%$ of the apparently healthy were unaware of their condition, an estimate that is comparable to that from the US (16\%) [34] but falls much lower than that from India (26\%) [35]. Furthermore, of all hypertensive individuals, one in two was unaware of their condition. This corroborates findings from the region $[22,33]$ and is consistent with the literature from other countries that have reported the "rule of halves," stating that "half of hypertensive patients are not known to health services" and thus remain unidentified [36]. In their recent review of global disparities, Mills and colleagues [5] note a substantial decrease in the proportion of hypertension unawareness in high-income countries in recent years that is not paralleled in low- and middle-income countries. Indeed, current estimates of prevalence rates of hypertension unawareness range from as high values as $80 \%$ in certain settings in India and Tanzania $[7,37]$ to much lower values in western Europe and the US [8, 38, 39], suggesting a shift to a rule of "third" or even lower in highincome countries.

Furthermore and consistent with studies conducted early in this century in the West [6], we found that younger individuals and those with low clinical risk profiles were at higher odds of being unaware of their condition, even after adjusting for a range of potential covariates. Published evidence on factors associated with hypertension unawareness has shown varying results. Some but not all show significant associations with diabetes $[6,8,22,38]$, obesity [6], hyperlipidemia [22], and alcohol consumption [40]. Our study suggests that physicians are particularly failing to detect hypertension in the younger, less obese, and relatively healthier individuals (no CVD and no family history of hypertension). These findings have relevance to national and global health system strategies and targets. For example, the screening initiatives for cardiovascular risk of the Lebanon Ministry of Public Health in its primary healthcare network, albeit commended, have focused on citizens who are 40 years and older [17], leaving behind the younger age groups. At the international level, the United Nations declaration of the Sustainable Development Goals (SDGs) calls for a onethird reduction in premature mortality from NCDs by 2030, and the $66^{\text {th }}$ World Health Assembly set a target of a $25 \%$ relative reduction in the prevalence of raised BP by 2025 . Hence, improving awareness and characterization of those "left behind" for early detection at the local level is the first step towards achieving targets at the global level.

There are certain limitations to this study, and our findings need to be interpreted within the context of the Lebanese healthcare system. Firstly, our data are crosssectional, and hence, causal associations cannot be established. Also, the study used self-reported data on measures concerning use of health services, and since these may be confounded by patient, physician, and health system-related factors during encounters, one cannot associate hypertension unawareness findings with specific behaviors of the patients or health workers. For example, participants might have received the needed medical attention but either diagnosis was not conveyed adequately, or they might have misunderstood the communication. In addition, and within the context of the Lebanon healthcare system that is largely pluralistic and fragmented relying mostly on out-of-pocket expenditure and a fee-for-service for outpatient services, participants may have delayed receiving medical attention to start with. Perhaps, an in-depth and a more thorough examination of healthcare practices in the local context, particularly in the primary care setting, is necessary to understand the contribution of those practices to the prevalence of hypertension unawareness in the country. Despite these concerns, this survey is the first national epidemiological household study in the country providing data on NCD and NCD risk factors and following the WHO standardized international guidelines and methodology. It also serves as a benchmark for future studies in Lebanon, allows comparisons with similar international studies, and provides baseline data for impact evaluation of the more recent initiatives on hypertension screening and NCD prevention in the country.

Although hypertension prevalence is well understood in the literature, the prevalence and correlates of hypertension unawareness are less so and vary depending on context. Hypertension, in general, comes without symptoms in the early stages, and individuals who are young and clinically least perceived to be at risk for hypertension are likely to be missed by the healthcare system, as our findings show. Whereas further studies are needed to examine the sociocultural and structural factors associated with hypertension unawareness in Lebanon, now is the time to start implementing multicomponent interventions, while optimizing and capitalizing on existing NCD prevention initiatives and screening practices to target the young and those with low clinical risk profiles. Our findings also invite reflections on the social epidemiology of hypertension unawareness in the country and in similar settings worldwide.

\section{Data Availability}

The dataset used and analyzed during the current study are available from the corresponding author on reasonable request.

\section{Disclosure}

This paper is based on secondary analysis of Noncommunicable Disease Risk Factor WHO-STEPS survey data and is part of the Student Research Project of the first two authors.

\section{Conflicts of Interest}

The authors declare that they have no conflicts of Interest. 


\section{Authors' Contributions}

Fatima Ghaddar, Lama Hammad, Rania A. Tohme, and Abla M. Sibai were responsible for conceptualization and visualization. Data curation and project administration were carried out by Rania A. Tohme, Nahla Hwalla, and Abla M. Sibai. Formal analysis was done by Fatima Ghaddar, Lama Hammad, and Abla M. Sibai. Funding acquisition was performed by Nahla Hwalla and Abla M. Sibai. Methodology was developed by Fatima Ghaddar, Lama Hammad, Rania A. Tohme, Tamar Kabakian-Khasholian, Nahla Hwalla, and Abla M. Sibai. Tamar Kabakian-Khasholian and Abla M. Sibai supervised the study. Fatima Ghaddar and Lama Hammad contributed equally to this work.

\section{Acknowledgments}

The authors would like to acknowledge Dr. Reina Alameddine for sharing her knowledge on the primary healthcare network in Lebanon and NCD prevention efforts in the country. The corresponding author received summer salary support from a grant from the International Development Research Centre, (grant reference number 10698100), Ottawa, Canada (https://www.idrc.ca), and from UK Research and Innovation as part of the Global Challenges Research Fund, grant number ES/P010873/1.

\section{References}

[1] J. Blacher, B. I. Levy, J.-J. Mourad, M. E. Safar, and G. Bakris, "From epidemiological transition to modern cardiovascular epidemiology: hypertension in the $21^{\text {st }}$ century," The Lancet, vol. 388, no. 10043, pp. 530-532, 2016.

[2] E. Gakidou, A. Afshin, A. A. Abajobir, K. H. Abate, C. Abbafati, and K. M. Abbas, "Global, regional, and national comparative risk assessment of 84 behavioural, environmental and occupational, and metabolic risks or clusters of risks, 1990-2016: a systematic analysis for the Global Burden of Disease Study 2016," The Lancet, vol. 390, no. 10100, pp. 1345-1422, 2016.

[3] P. M. Kearney, M. Whelton, K. Reynolds, P. K. Whelton, and J. He, "Worldwide prevalence of hypertension," Journal of Hypertension, vol. 22, no. 1, pp. 11-19, 2004.

[4] T. A. Gaziano, D. Prabhakaran, and J. M. Gaziano, "Global burden of cardiovascular disease," in Braunwald's Heart Disease: A Textbook of Cardiovascular Medicine, E. Braunwald, D. L. Mann, and D. P. Zipes, Eds., pp. 1-20, Elsevier Health Sciences, 2015.

[5] K. T. Mills, J. D. Bundy, T. N. Kelly et al., "Global disparities of hypertension prevalence and control," Circulation, vol. 134, no. 6, pp. 441-450, 2016.

[6] W. Maziak, U. Keil, A. Döring, and H. W. Hense, "Determinants of poor hypertension management in the community," Journal of Human Hypertension, vol. 17, no. 3, p. 215, 2003.

[7] P. Devi, M. Rao, A. Sigamani et al., "Prevalence, risk factors and awareness of hypertension in India: a systematic review," Journal of Human Hypertension, vol. 27, no. 5, p. 281, 2013.

[8] I. Guessous, M. Bochud, J. M. Theler, J. M. Gaspoz, and A. Pechère-Bertschi, "Trends in prevalence, unawareness, treatment and control of hypertension in Geneva, Switzerland," PLoS One, vol. 7, no. 6, Article ID e39877, 2012.
[9] J. Kayima, R. K. Wanyenze, A. Katamba, E. Leontsini, and F. Nuwaha, "Hypertension awareness, treatment and control in Africa: a systematic review," BMC Cardiovascular Disorders, vol. 13, no. 1, p. 54, 2013.

[10] O. I. Ekwunife, P. O. Udeogaranya, and I. L. Nwatu, "Prevalence, awareness, treatment and control of hypertension in a Nigerian population," Health, vol. 2, no. 7, pp. 731-735, 2010.

[11] C. Nejjari, M. Arharbi, M. T. Chentir et al., "Epidemiological trial of hypertension in north africa (ETHNA): an international multicentre study in Algeria, Morocco and Tunisia," Journal of Hypertension, vol. 31, no. 1, pp. 49-62, 2013.

[12] R. Malhotra, T. Puoane, C. Hoyo, G. Hughes, and T. Ostbye, "Prevalence and awareness of hypertension in an urban township of South Africa: compelling need for action," Ethnicity \& Disease, vol. 18, no. 4, pp. 401-402, 2008.

[13] X. L. Feng, M. Pang, and J. Beard, "Health system strengthening and hypertension awareness, treatment and control: data from the China Health and Retirement Longitudinal Study," Bulletin of the World Health Organization, vol. 92, no. 1, pp. 29-41, 2013.

[14] O. A. Sanuade, S. Boatemaa, and M. K. Kushitor, "Hypertension prevalence, awareness, treatment and control in Ghanaian population: evidence from the Ghana demographic and health survey," PLoS One, vol. 13, no. 11, Article ID e0205985, 2018.

[15] A. M. Sibai, A. Fletcher, M. Hills, and O. Campbell, "Noncommunicable disease mortality rates using the verbal autopsy in a cohort of middle aged and older populations in Beirut during wartime, 1983-93," Journal of Epidemiology \& Community Health, vol. 55, no. 4, pp. 271-276, 2001.

[16] IHME-Compare GBD, Institute of Health Metrics and Evaluation, University of Washington, Washington, DC, USA, 2016, https://vizhub.healthdata.org/gbd-compare/.

[17] R. Yamout, S. M. Adib, R. Hamadeh, A. Freidi, and W. Ammar, "Screening for cardiovascular risk in asymptomatic users of the primary health care network in Lebanon, 2012-2013," Preventing Chronic Disease, vol. 11, p. E120, 2014.

[18] Health MOPH, Launches the National Campaign to Raise Awareness on Hypertension Awareness \& Taking Actions are Means to Fight This Silent Killer, https://executive-bulletin. $\mathrm{com} /$ health/moph-launches-the-national-campaign-to-raiseawareness-on-hypertension-awareness-taking-actions-aremeans-to-fight-this-silent-killer, 2019.

[19] R. A. Tohme, A. R. Jurjus, and A. Estephan, "The prevalence of hypertension and its association with other cardiovascular disease risk factors in a representative sample of the Lebanese population," Journal of Human Hypertension, vol. 19, no. 11, p. 861, 2005.

[20] S. G. Mallat, S. A. Samra, F. Younes, and M. T. Sawaya, "Identifying predictors of blood pressure control in the Lebanese population-a national, multicentric survey-I-PREDICT," BMC Public Health, vol. 14, no. 1, p. 1142, 2014.

[21] R. Farah, R. K. Zeidan, M. N. Chahine et al., "Predictors of uncontrolled blood pressure in treated hypertensive individuals: first population-based study in Lebanon," The Journal of Clinical Hypertension, vol. 18, no. 9, pp. 871-877, 2016.

[22] D. Matar, A. H. Frangieh, S. Abouassi et al., "Prevalence, awareness, treatment, and control of hypertension in Lebanon," The Journal of Clinical Hypertension, vol. 17, no. 5, pp. 381-388, 2015.

[23] L. Riley, R. Guthold, M. Cowan et al., "The World Health Organization STEPwise approach to noncommunicable disease risk-factor surveillance: methods, challenges, and 
opportunities," American Journal of Public Health, vol. 106, no. 1, pp. 74-78, 2016.

[24] P. Geldsetzer, J. Manne-Goehler, M.-E. Marcus et al., "The state of hypertension care in 44 low-income and middleincome countries: a cross-sectional study of nationally representative individual-level data from 1.1 million adults," The Lancet, vol. 394, no. 10199, pp. 652-662, 2019.

[25] M. C. Chamieh, H. J. Moore, C. Summerbell, H. Tamim, A. M. Sibai, and N. Hwalla, "Diet, physical activity and socioeconomic disparities of obesity in Lebanese adults: findings from a national study," BMC Public Health, vol. 15, no. 1, p. 279, 2015.

[26] M. E. Gee, N. Campbell, N. Sarrafzadegan et al., "Standards for the uniform reporting of hypertension in adults using population survey data: recommendations from the World Hypertension League Expert Committee," The Journal of Clinical Hypertension, vol. 16, no. 11, pp. 773-781, 2014.

[27] K. Bell, J. Twiggs, B. R. Olin, and I. R. Date, "Hypertension: the silent killer: updated JNC-8 guideline recommendations," Alabama Pharmacy Association, vol. 334, p. 4222, 2015.

[28] A. M. Sibai, C. Costanian, R. Tohme, S. Assaad, and N. Hwalla, "Physical activity in adults with and without diabetes: from the 'high-risk'approach to the 'population-based'approach of prevention," BMC Public Health, vol. 13, no. 1, p. 1002, 2013.

[29] D. J. Hyman and V. N. Pavlik, "Characteristics of patients with uncontrolled hypertension in the United States," New England Journal of Medicine, vol. 345, no. 7, pp. 479-486, 2001.

[30] A. Tailakh, L. S. Evangelista, J. C. Mentes, N. A. Pike, L. R. Phillips, and D. E. Morisky, "Hypertension prevalence, awareness, and control in Arab countries: a systematic review," Nursing \& Health Sciences, vol. 16, no. 1, pp. 126-130, 2014.

[31] C. El Bcheraoui, Z. A. Memish, M. Tuffaha et al., "Hypertension and its associated risk factors in the kingdom of Saudi Arabia, 2013: a national survey," International Journal of Hypertension, vol. 2014, Article ID 564679, 8 pages, 2014.

[32] M. R. Khdour, H. O. Hallak, M. Shaeen, A. S. Jarab, and Q. N. Al-Shahed, "Prevalence, awareness, treatment and control of hypertension in the Palestinian population," Journal of Human Hypertension, vol. 27, no. 10, p. 623, 2013.

[33] A. M. Yusufali, R. Khatib, S. Islam et al., "Prevalence, awareness, treatment and control of hypertension in four Middle East countries," Journal of Hypertension, vol. 35, no. 7, pp. 1457-1464, 2017.

[34] R. Paulose-Ram, Q. Gu, and B. K. Kit, Characteristics of US Adults with Hypertension Who are Unaware of Their Hypertension, 2011-2014, pp. 1-8, US Department of Health \& Human Services, Centers for Disease Control and Prevention, National Center for Health Statistics, Hyattsville, MA, USA, 2017.

[35] A. N. Shukla, T. Madan, B. M. Thakkar, M. M. Parmar, and K. H. Shah, "Prevalence and predictors of undiagnosed hypertension in an apparently healthy western Indian population," Advances in Epidemiology, vol. 2015, Article ID 649184, 5 pages, 2015.

[36] L. Weinehall, B. Öhgren, M. Persson et al., "High remaining risk in poorly treated hypertension: the 'rule of halves' still exists," Journal of Hypertension, vol. 20, no. 10, pp. 2081-2088, 2002.

[37] N. R. Mosha, M. Mahande, A. Juma et al., "Prevalence, awareness and factors associated with hypertension in North West Tanzania," Global Health Action, vol. 10, no. 1, Article ID 1321279, 2017.
[38] U. Lindblad, J. Ek, J. Eckner, C. A. Larsson, G. Shan, and L. Råstam, "Prevalence, awareness, treatment, and control of hypertension: rule of thirds in the Skaraborg project," Scandinavian Journal of Primary Health Care, vol. 30, no. 2, pp. 88-94, 2012.

[39] T. Nwankwo, S. S. Yoon, V. Burt, and Q. Gu, "Hypertension among adults in the United States: National health and nutrition examination survey, 2011-2012," NCHS Data Brief, vol. 133, pp. 1-8, 2013.

[40] S. Basu and C. Millett, "Social epidemiology of hypertension in middle-income countries," Hypertension, vol. 62, no. 1, pp. 18-26, 2013. 